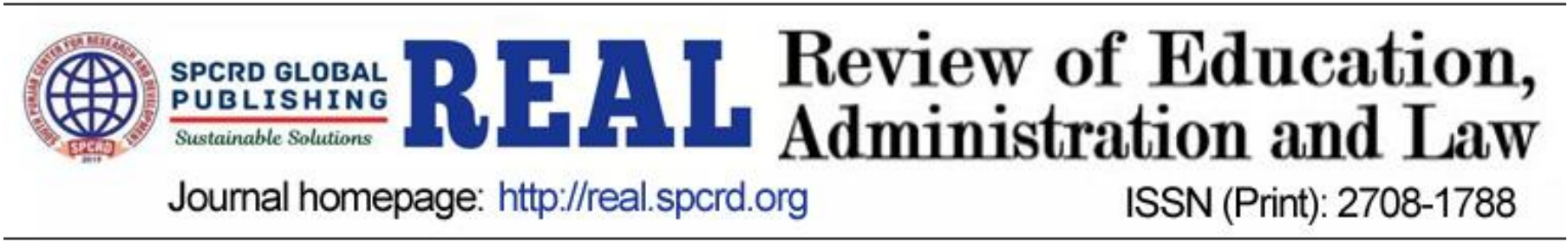

\title{
The Written Discourse of Female College Students about Formal Literacy and Self: A Study Analysis
}

\author{
a Rabia Mohsin, ${ }^{\text {b }}$ Muhammad Akbar Sajid \\ ${ }^{\text {a }}$ Assistant Professor Govt post- graduate Emerson college, Multan \\ b Assistant Professor/HOD, NUML, Multan campus, Pakistan: masajid@numl.edu.pk
}

Corresponding author's email address: masajid@numl.edu.pk

\begin{tabular}{l}
\hline ARTICLE DETAILS \\
\hline History: \\
Accepted 11 April 2019 \\
Available online 3o June 2019
\end{tabular}

Keywords:

Formal Literacy, Self, Representation, Written

Discourse, Construction

JEL Classification:

P36, J29, A31

DOI: $10.47067 /$ real.v2i1.9

\section{ABSTRACT}

Self is a fluid construct. Its construction and representation vary according to different contexts and other variables. Female selfconstruction and representation is a crucial domain which is affected by many social factors. The present research deals with construction and representation of self. The data for the present research has been collected from the 4 colleges, 2 belonging to urban area and 2 of peripheries. The participants of the research are girls of 1st year and 4 th year. The present research analyses the construction and representation of self as a result of formal literacy. It also considers how formal literacy plays a role in the construction and representation of self. For the present research, the researchers have collected the data from the mentioned 4 colleges. The participants of the research are 200 female students, including 100 from 1 st year and 100 from 4 th year. The present research employs an amended model to analyze the data. The amended model consists of Fairclough's (2012) critical social analysis, Gee's (1999) cultural model of discourse and Street's (1984) ideological model of literacy. The data has been analyzed keeping into mind the 9 analytical devices i.e. implicature, identity, metaphor, comparisons, representations, back grounding, inclusion/exclusion, dialogically and difference. Moreover, the researchers have categorized the data into the dominant emerging themes, which have been classified and analyzed under separate headings, these dominant emerging themes are, religiosity, family background, identity (naming), desires and self, self through lexicalization, roles and relationships, conceptual metaphors and use of 1st person pronoun (I/we). The data has been analyzed qualitatively and quantitatively. Based on the analysis of data the findings of the research suggest that self is not an absolute term, its construction and representation keeps on changing because of different variables, one of them is formal literacy. Moreover, the study contends that construction and representation of self is an ever-ongoing process. 
(C) 2019 The authors. Published by SPCRD Ltd. This is an open access article under the Creative Commons Attribution-NonCommercial 4.0

\section{Introduction}

Socio-economic conditions play an important role in the construction and representations of self among individuals. Self is directly influenced the way one gains prosperity or suffers loss in terms of economy. The present research views self-construction and representation from the view of female college students. Data for the present research has been collected from the students of female college of district Multan, Pakistan. Hall (2003) considers representation as a means of meaning production. He considers representation not the reality rather recapitulation of reality. Reality finds its meanings when viewed through the specific prism of culture. Language, culture, and representation are related to oneanother. Language serves not only the purpose of communication rather it is also one of the powerful tools to judge one's self. The use of language by an individual reveals his/her linguistic as well as social identity. Hudson (1987) asserted that speech is a type of social behavior which never exists in isolation. Baker (1998) opines that individuals' attitudes are the result of intentions, behavior. cognition and affective responses. These attitudes further urge the individuals to act in a way. Corson (1997) holds that educational institutions shape individuals' self through specific discursive practices. Formal literacy is one of the significant features along with economy to shape and represent self among female college students. The present article attempts to find out how the students' of first year construct their self and what change does occur in it when they are a grade up in formal literacy. It also highlights the other factors that influence the construction and representation of self among female college students of the college of Multan district, Pakistan.

Self can be defined as totality of beliefs and values which the individuals cherish, it can also be an organized and complex system based on individuals 'perception. Whatever individuals perceive finds representation through language. Saussure (1983) claims that language not only reveals some preexisting reality rather it is a means of constructing reality. Halliday (1975) asserted that language develops as a social meaning making process as a result of communication of two language users. Gal (1991) maintained that in many cultures use of language and the emergence of self are linked with one another. Therefore, construction of self can be considered as cultural phenomena which can be shaped and reshaped through language. Language is not static rather it is dynamic. Same is the case with self. It never remains same. Both are fluid like and changes with changing socio-political scenario and both are influenced by sociological, religious, geographical and many other factors. In Pakistani context as well, it is observed that formal literacy influences an individual's self along with other factors including religion, geography, ethnicity, economy etc. This difference is revealed by the language used by both individuals. The linguistic choices used by females to reflect the self they possess. Formal literacy is among one of the factors that influences the construction and representation of self-image of females.

Formal literacy is among various forms of literacies which is structured, having proper intentions and ideologies which are imparted through educational institutions. Educational institutions have definite syllabus to teach which are based on government policies. Students getting education through these institutions undergo change in self which is reflected through their language. Most often it is preplanned that what type of literacy is to be imparted and to whom. This is done to make the individuals behave in a certain manner. As we are the by-product of what we have internalized in form of so many literacies including the formal one.

In this regard, Street (1984) considers literacy as a social practice which have always sociological epistemological principles. He further argues that propagation of literacy is ideological. According to him 
literacy is a social act from the very outset, it is most often loaded with policy presumption and have specific ideologies that influence the individuals. All this is achieved through language used, which plays a significant role in the construction of self. However, various cultural factors do influence an individual's perception and representation of self.

Corson (1997) regarded educational institutions the key factor in shaping self-identities. He opined that highly social practices are inculcated in the individuals through these highly valuable institutions of education sector. These provide a way to think about culture and thoughts are shaped that are usually multilayered, diverse sometimes fragmented and variable.

Self is a very complex term to be explained. According to Plato (380.B.C) it may be related to two worlds of seen and unseen, because explaining self requires answer of two questions, who am I, and the answer of it is usually comes by telling the name, and if the question is projected as what I am? that answer may be that I am body and soul. One related to the seen world of man and other spiritual world which in unseen, but one is incomplete without the other. Plato consider one changeable and other immortal but Hume(1739) considered context most important for the emergence of self. Derrida (1988) also regarded language and context as important factors in the construction of self. Societal values, power relations and policies are projected through educational institutions to shape minds of the individuals hence, the institutions and self-construction and representation can be regarded as directly linked to each other. Otlowski (2003) maintained that in Japan text books are very important in shaping self, a stereotypical image of females is projected as are shown house makers and mostly as mothers, when the female students go through these texts get a strong influence in construction of their selves. Moreover, textbooks highly influence construction of self. These textbooks are usually staples of learning and an average student till reaching to secondary level goes through approximately 32,00o pages, what is presented on these pages do influence sense of self of these individuals.

Norton and Toohey (2002) suggested that while writing poem, letter or essay one not only brings forth history but also represents one's identity, because language is not only a sign system rather it is a social practice too. The words uttered get their value by the meanings assigned to them by their users, and the context in which they are spoken. Hence, every word has an ideology behind it and hence, the identities of individuals are usually mediated between texts they utter and write. Meads (1934) regarded that language and literacy has a significant role in the construction of self.

\section{Literature Review}

Kakar (1979) in "cultural ideal and social reality" stated that in Indian childhood girls are usually brought up by their female caretakers who influence their lives as they train them how to behave in life and perform their roles in social life. Josselson (1987) maintained that female self is shaped by their family and acquaintances. Ahmed (1999) also asserted that childhood brought up is a key factor in construction of self in South Asia. Zubair (1999-2001) considered literacy as a powerful site to shape self. The text taught to students directly or indirectly influence the students and serve as a powerful factor in the construction of self, especially for the female students. In Pakistani setup the females are usually brought up and trained in somewhat different manner from the boys of their houses, these females when given education in formal set ups, schools, colleges and universities, develop in them critical awareness and hence, they will be motivated to change their cognition and pragmatics. They start empowering themselves and find it totally Islamic and a modest step to come out of their house and work with their male counterparts. Zubair (2007) also maintained that the use of figurative language by the female of South Asia clearly reveal how the social realities are constructed among the females of these areas. Konate 
(2010) brought out that the socio-economic factor is also one of the major factors in the construction of self. Hussain et al (2008) asserted that in Pakistan parents usually behave differently with their boy and girl child which is one of the reasons of different self-construction among them. Ambreen and Mohyuddin (2012) also revealed that societal behaviors and different forms of education for boys and girls is a reason that influence construction of self among male and females. Females are provided with least high quality formal education as it is typically thought in patriarchal societies like Pakistan that the role of women in social life is just to run their homes and hence, usually parents select different fields for their sons, Moreover societal expectations from girls are different which usually result in different self-construction among females.

Female self-construction is not only a matter of cognition but also it is influenced by socio-logical factor also. Societal norms values and beliefs are of utmost importance for the emergence, construction, and representation for self. Along with other factors in the present article the researcher has considered formal literacy as a key factor in the construction and representation of self. Different theories presented by different theorists form the foundation of the research and provide a framework for the present research.

\subsection{Representation and Reality}

Reflective theory holds that language used by individuals reflects true meaning lying in the events and objects. The intentional theory states that meanings reside within the intentions of the individuals which are expressed through language. The third theory asserts that meanings are contextual and are usually constructed in and through language Hall (2003). He claims that representation is not reality rather it is recapitulation of reality and every expression finds its culture. The societal norms, values, beliefs, and exceptions serve as a prism to show the reality. Words uttered by individuals although reflect the attitudes beliefs and personality of the speakers but to find out the exact meanings of the spoken or written text the context is crucial of vital significance.

Erikson (1968) talks about identity development theory. He argues that lenses of discourse and discourse construction are significant in this regard. The lenses discourse or discursive approach considers both text and context in order to find out meanings, whereas the second lens revolves around three processes, agency, difference or sameness and consistency or change. It looks for it is I who constructs identity, me who undergoes construction, how is one different or same in expression from others and how someone remains constant in constantly dynamic environment.

\subsection{Discursive action of language}

Meads (1934) believes that language capability of an individual develops along with an individual's development. He considers it dynamic. a fluid that is ever changing as a social practice. As the societal experiences, activities and values undergo change with the passage of time. Similarly, language changes and plays a role in construction of self.

Whorf (1956) provided typological stance of language and suggested that grammatical options taken by individuals influence their sense of self. This typological diversity considers language as a discursive action and it presents a complete system and mechanism of language use in construction of self. Besides, cultural values embedded in language also influence self-construction and representation. These drive the individuals to talk and behave in some specific way. Hence, for the construction of selflanguage is considered as a significant symbol, a typological variety and a force for action. 


\subsection{Discourse: Self and ideologies}

In any society language is presented in the form of discourse. It serves an identity kit for the users and provide clues about them that what they think, how they behave and represent themselves in specific situation. A socially accepted use of language may be regarded as discourse. Discourses are always in change of flux and so is self, hence one can find a strong connection between both. Beliefs are ideological if a significant proportion of persons shape them, they coherently make a system and through them power is exercised in the society. Kress (1989) considered that ideologies have cognitive bases that they use tool of language for their projection. We say that discourses are mostly ideological. Fairclough (2003) consider discourse is language use as a social practice. Leeuwen (2007) regarded discourse are powerful source of expressing social realities and can influence social practices in vogue, as they reflect the social practice, have the ability to transform any social practice and also legitimize the social practices influence individual's sense of self as language is not only saying words but doing and action. When the typical ideologies are repeated and injected in the individual's in the form of different occasions and events, at this stage ideologies serve as a driving force for the construction of self among the individuals. Individual perception and representation of this perception is linked to the place of their living. Based on existing knowledge in their minds their actions are governed. In the present article one of the variables to judge construction of self is formal literacy, hence out what change in self is represented by the change in literacy level.

\section{Methodology}

The data for the present research comes from the female college students of district Multan (Makhdoom Rasheed) during the year (2016-17). The data was collected from the female students when they were the students of 1st year in (2016) and again when those students were promoted to 2nd year in (2017). The students were asked to write an essay on self when they were in 1st year and 2nd year, respectively. The researchers collected the data from the willing participants. They were assured that the data would be used for the research purpose. As one of the researchers is a lecturer in the female college Makhdoom Rasheed District, Multan. Therefore, it became easier to persuade the students to provide data through written essays on self. Twenty-five (25) students (when they were in 1st year) were the participants from whom data was collected in 1st year and 2nd year. It has purposely been done by the researchers to have essay written from the same participants about their self to know what role formal literacy and economy (1st year and 2nd year) can play in the perception and representation of self as expressed by the participants through their written essays both in 1st year and 2nd year.

The researchers have carefully gone through the written essays of the students to know how they have represented their self through their written discourse. One of the variables is time factor as well as economy. The essays written by each student about herself when she was in 1st year and 2nd year were carefully compared to know what changes have taken place about the perception and representation ofself as illustrated through the written essays.

A triangulation has been done to analyze the data concerning perception and representation of self through the written Discourse of the mentioned female college students by drawing upon Street's (1984,) ideological model of literacy), Gee's (1999, cultural model of discourse). And Fairclough's (2012, model of critical social analysis CSA). This has been done to analyse the data because literacy is influenced by social cultural, political, economic, and religious factors. Therefore, keeping in mind these factors Street's 1984 ideological model of literacy, Gee's 1999 model of discourse and Fairclough's 2012 model of critical social analysis have been adapted in accordance with the existing data. 
Street(1984) asserts that literacies are ideologically rooted in particular world- views. He views literacy in3-dimensional form from socio-cultural point of view which interlocks cultural, operational, and critical dimensions. Language is an embodiment of social beliefs which are revealed through the words individual utter, write or use to communicate. He considers literacy as a social practice. Gee's (1999) model of discourse asserts that different individuals think, talk and represent themselves in different ways which actually emerge from their different ways of thinking and belief systems. He calls them cultural models. These cultural models illustrate who they are and what they are doing. For the linguistic analysis of data, Fairclough's model of CSA Has been applied.

The researchers have analyzed data by focusing on 9 analytical devices i.e. implicature, metaphor, comparisons, identity, representations, inclusion/exclusion, back-grounding, dialogically and the differences. For the purpose of analysis, the data has been categorized into emerging themes which are considered important for the construction and representation of self among the participants. These 8 categories are family background, identity at the level of naming, religiosity, self through lexicalization, desires and self, conceptual metaphors, roles, and relationships and use of I 1st person pronoun. The collected data has been analyzed quantitatively as well as qualitatively.

\section{Data Analysis}

The data gathered for the present study contains the following themes which are analyzed keeping in-view the analytical categories of Fairclough's CSA model (2012).

- Family Background

- Identity

- Religiosity

- Self through lexicalization

- Desires and self

- Conceptual Metaphor

- Roles and Relationship

- Use of 1st person pronoun

Self is influencedand reshaped by certain factors. The data reveal that the influence of family background and economy are of much importance in the construction and representation of self. It is obvious from the data that two participants have revealed their family background in first year but not in 2nd yea to construct their self. It can be inferred here as Friedan (2010) opines that the individuals should try to find out their identity leaving their family identity behind. A change inself whether positive or negative is found here that the participants who first clearly revealed their family background whether as poor, rich or noble have now not declared it after a span of one year. It can also be inferred that as it is considered that in the post-postmodern era, people take their past as unpleasant reality and are afraid of revealing it and think it not good to reveal their past which may be the result of frustration or any inward psychological disturbance. It can also be taken as internal cowardice of the individuals that they are ashamed of revealing their poor status. As the students are of rural area college it might be taken as an attempt to find their self beyond the family ties and bond. Another change is seen while going through the data that two students who did not reveal their family background expressed clearly that one belongs to the noble family of the area and the other is not ashamed of telling her poor family status. It could be a result of formal literacy that the influence of family name and background whether good or bad is an integral part of these participants' identity. 
Fairclough (2003) takes the individuals personal identity with special prestige and pride which makes an individual distinguished one. The analysis of the data illustrates that all the participants have revealed their name both in 1st year as well as in 2nd year. As it is oftenthought that people of the rural area are usually not as much open and liberal as the people living in cities are. But revealing their identity at the level of naming is a clear proof that somehow these students of college have gained confidence that they are not afraid of telling their names. It might be said that these students studying in rural area colleges have been given chances to make themselves literate and hence they are able to gain confidence and hence reveal their name. This is how it can be asserted that formal literacy imparts confidence among the students.

Gramsci (2004) maintains that various ideologies drive individuals and religion is among one of them. Concerning one's faith there is no final definition of religion it can be regarded as some supernatural power or absolute power which drives the individuals to behave in a certain way. The researchers have tried to co-relate the religious ideas from the participants to their self.

The following chunks taken from the data can be presented here as illustrations.

- I am a true Muslim. I believe that God is one and merciful. I try to offer prayers five time a day.

- I would become the same that Allah want. I would become so good that Allah forgives me on the day of judgment because this world is no more than an illusion.

- I love and respect mosque because mosque is a house of our loving God.

Here, the use of adjective "true" with Muslim is full of meanings. The participant has distinguished herself from others positively by using comparative technique. She could have written it as "I am a Muslim". It implies that she is true and merciful, and the others may not be. Furthermore, she has used the pronoun I which shows certainty, individuality, and authenticity on her part. Ivanic (2001) asserts that use of 1st person pronoun signifies many things in written discourse such as authority certainty, an opinion holder and authorial I.

The technique of difference is obvious in the statement of the girl "My favorite place is Makkah". Some of the participants have plainly revealed their attachment with the religion whereas others have distinguished themselves by using certain adjectives, showing their love for the sacred and religious places which shows certain bifurcation among the participants regarding the theme of religion while describing themselves and associated their self with religion and their love for sacred places like Makah and Madina.

Conboy (2007) suggested that ideology can be persuaded or established using metaphors in order to make it common sense. The sentences

"I would becomegood that Allah forgive me on the day of judgment because this world is no more than illusion".

"I love and respect mosque because mosque is a house of our loving God".

Are ideologically loaded about self-construction and representation. According to Lakoff (1995) we live in metaphors which cannot be separated from language. The examples cited above connote that religious ideology is injected to the middle class. The use of the word "illusion" implies that the self being 
discussed is religiously religiously imprisoned self. Right from the beginning religious ideology is inculcated among the individuals as I love and respect mosque because mosque is a house of our loving God. Here a popular societal ideology is seen that God lives in mosque. Hence, we can safely assume that religion is a key point in the construction of self, as it is apparent from the selected chunks that most of the participants have shown their religiously dominated self.

The analyses of the data reveals that besides Formal Literacy, economy is one of the significant factors which influences one's perception and representation of self. The analysis unfolds that self is an ongoing process. However, there are multiple factors which continuously keep on influencing self. Along with formal literacy the role of economic prosperity or otherwise cannot be ignored

\section{Conclusion}

Based on the analysis of the data the study finds that construction and representation of self is not static rather dynamic process. However, "self" varies from male gender to female gender as well. Time, economy, increase in formal literacy, sociopolitical conditions and religion are significant factors to make self like a fluid. The variables mentioned above play a significant role in making construction and representation of self an ongoing process. It is right to conclude that not only we grow physically, rather mentally as well.

\section{References}

Ahmed, K. (1999). Adolescent development for South Asian American girls' in Gupta, S.R.(ed.). Emerging Voices: South American Women Redefine Self, Family and Community. New Dehli: Sage.

Ambreen, M., \& Mohyuddin, A. (2012). Cultural portrait of women in a Punjab village. Perception of people regarding gender and roles and literacy. (Vol. 1). International Journal of Arts and Commerce.

Baker, R.E. et al. (1998) Mutations synthetically lethal with cep1 target S. cerevisiae kinetochore components. Genetics 149(1):73-85.

Conboy, M. (2007). The Language of News. London: Routledge.

Corson, D. (1997). Critical Realism: An Emancipatory Philosophy for Applied Linguistics?, Applied Linguistics, Volume 18, Issue 2, June 1997, Pages 166-188

Derrida, J. (1988).Critical Inquiry: Vol. 15, No. 4 (Summer, 1989), pp. 767-776. The University of Chicago Press.

Erikson, Erik H. (1968). Identity: Youth and crises. New York: Norton.

Fairclough, N. (2003). Analysing discourse: Textual analysis for social research. London: Routledge.

Fairclough, I., \& Fairclough, N. (2012). Political discourse analysis London: Routledge.

Friedan, B. (2010). The Feminine Mystique: The Penguin Group.

Gal, S. (1991). Between speech and silence: The problems or research on language and gender in Michaela di Leonardo (ed.). Gender at the Crossroads of Knowledge: Feminist Anthropology in the Postmodern Era. Berkley, Los Angeles, Oxford: University of California Press.

Gee, J. (1999). An Introduction to Discourse Analysis: London: Routledge.

Gramsci, I.P. (2004). Politics of Language: Toronto: University of Toronto Press.

Hall, S. (2003). The Work of Representations, U Knjizi Representation: Cultural Representations and Signifying Practices, ed. by S. Hall.

Halliday, M.A.K. (1975). Learning to mean: Explorations in the development of Language. London: Edward Arnold.

Hudson,N. G. and Allen, J. C. The Institute Clauses Handbook: Arbitration International, Volume 3, Issue 3, 1 July 1987, Pages 269-271. 
Hume, D. (1739/1888/1978). A Treatise of Human Nature (ed. L. A. Shelby-bigge, 2nd edn. rev. Ph. Nidditch). Oxford. Oxford University Press.

Ivanic, R. (1995). Writer identity. Prospect, 10(1), 8-31.

Ivanic, R, \& Camps, D. (2001). I am how I sound: Voice as representation in L2 writing. Journal of second language writing, 10, 3-33.

Josselson, R. (1987). Finding herself: Pathways to identity development in women. Jossey-Bass.

Kakar, S. (1999). Indian childhood: Cultural Ideals and Social Reality. Delhi: Oxford University Press.

Konate, M. (2010). The Effects of Literacy on Rural Women in Mali: Transformation through Empowerment. Michigan State University.

Kress, G. (1989). Linguistic Processes in Sociocultural Practice. Oxford: Oxford University.

Lakoff, R. (1995). "Women and Silence". In K. Hall and M. Bucholtz (eds.) Gender Articulated: Language and Socially constructed self. New York. Routledge.

Van Leeuwen, T. (2007). Legitimation in discourse and communication. Discourse \& Communication, 1(1), 91-112.

Theberge, L., \& Kernaleguen, A. (1979). Importance of Cosmetics Related to Aspects of the Self. The Downside Review, 48(3), 3-28

Saussure, F. de. (1983).Course in General Linguistics. Translated by R. Harris. London: Duckworth. .

Street, B. V. (1984). Literacy in theory and practice. Cambridge University Press, 9.

Meads, G.H. (1934). Mind, Self and Society. Henceforth, MSS.

Norton. B., \&Toohey, K. (2002). Identity and language learning, In R.B. Kaplan (Ed.). The Oxford handbook of applied linguistics (pp 115-123).Oxford. England: Oxford University Press.

Otlowski, M.(2003). Ethnic diversity and Gender Bias in EFL Textbooks. Retrieved March14, 2008 from http://asian-efl-journal,com/june_2003_mo.php,1-3.

Whorf, B. L. (1956). Language, thought, and reality: Selected Writings of Benjamin Lee Whorf. New York. NY: John Wiley.

Zubair, S. (1999). Women's Literacies in a Rural Pakistani Community: An Ethnographic Study.

Zubair, S. (2001). Literacies, gender and power in rural Pakistan. Literacy and development: Ethnographic perspectives, 188-204.

Zubair, S. (2007). Silent birds: Metaphorical constructions of literacy and gender identity in women's talk. Discourse Studies, 9(6), 766-783. 